DE GRUYTER

OPEN

10.2478/cris-2014-0001

\title{
THE FIBONACCI SEQUENCE: NATURE'S LITTLE SECRET
}

NIKOLETTA MINAROVA

Fibonacci: a natural design, easy to recognise - yet difficult to understand. Why do flowers and plants grow in such a way? It comes down to nature's sequential secret... This paper discusses how and when the Fibonacci sequence occurs in flora. 


\section{FIBONACCI IN NATURE}

When you sit in a garden and look around, you can easily recognise several natural designs. You see bees buzzing around flowers with neatly arranged petals, trees whose trunks are surrounded by pinecones with their distinctly patterned bracts, and maybe a little snail with a spirally shelled house on its back. But what exactly makes these designs look the way they do?

It may sound weird, but it is actually a mathematical sequence, called the "Fibonacci series" which can explain this phenomenon. Actually, this sequence of numbers, which seems to mysteriously pop up everywhere, is not as weird as you may think. In fact, you will find that it would be weird if it was not found there at all.

The Fibonacci Sequence is a pattern of numbers generated by a particular rule (Dunlap, 1997, p. 37). It starts with 0 and 1 . These two numbers are added to get 1 , then the new 1 is added to the previous 1 to make 2. This pattern repeats itself as seen below:

$$
\begin{aligned}
& 0+1=1+1=2 \\
& 1+2=3 \begin{array}{l}
2+3= \\
3+5
\end{array} \\
& 5+8=13
\end{aligned}
$$

$0,1,1,2,3,5,8,13,21,34,55,89, \ldots$

This is known as a recursive sequence defined by the equations:

$$
F 1=1, F 2=1 \text {, and } F_{n}=F_{n-1}+F_{n-2} \text { for all } n \geq 3
$$

Fn represents the $n^{\text {th }}$ Fibonacci number.

\section{CREATING A FIBONACCI SPIRAL}

When arranged in a certain way, the Fibonacci sequence creates a special spiral pattern. This pattern can be found in many places in nature.

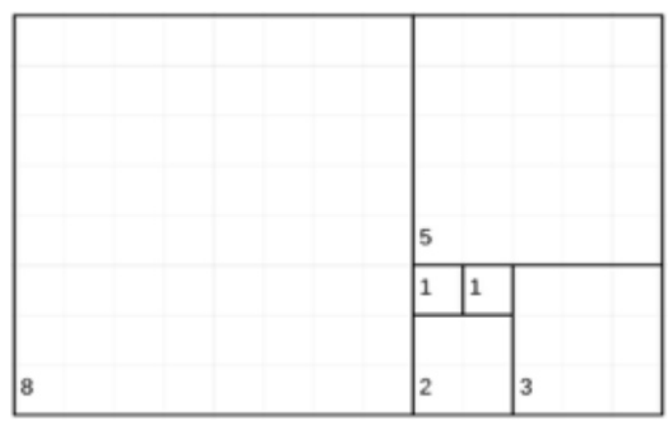

1. Squares are drawn based on the Fibonacci sequence as is seen in the picture to the right. Graph paper should be used so that the spiral is perfect. The $1 \times 1$ squares are drawn first and then more squares are added based on the sequence of numbers. 


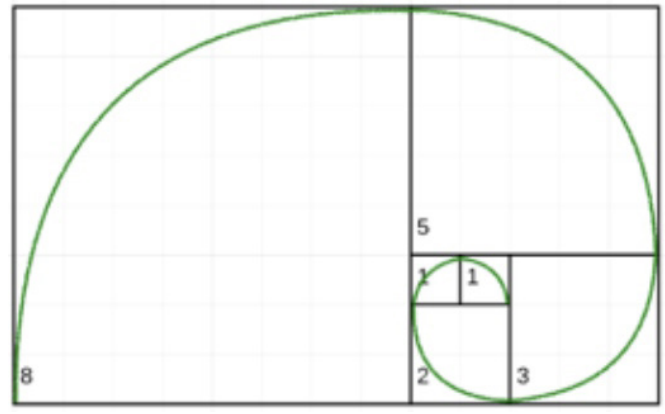

2. The next step is to draw curves in every square, creating a spiral-like shape. A quarter of a circle is drawn in every square. This spiral can be expanded by adding more squares based on the Fibonacci sequence.

The Fibonacci spiral is a good approximation of a shape which occurs in many places in nature, such as in snail shells or even the spiral of a hurricane (Constance, 2010, p. 1). However, it is not considered a 'true' mathematical spiral, as it is composed of fragmented segments of a circle and does not scale down in size (Knott, 2010). The spiral creates a line from the middle of the spiral and increases by a factor of the golden ratio, 1.618, in every square (Norton, 1999).

\section{CREATING A FIBONACCI SPIRAL}

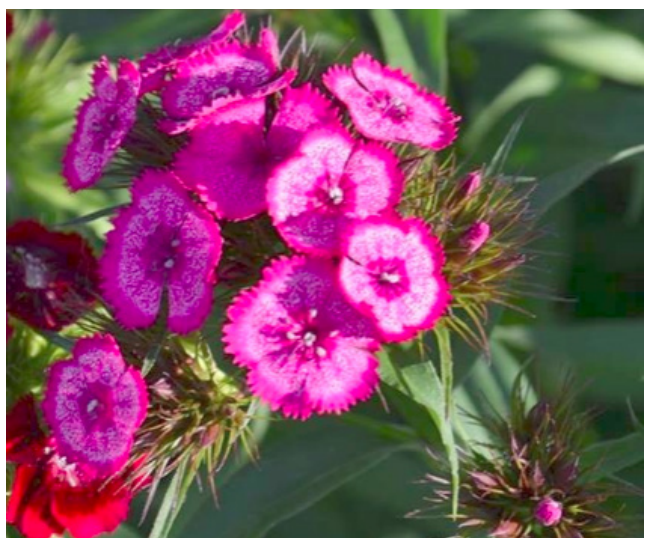

The Fibonacci sequence occurs in the number of many flowering plants. Think about how many plants you know which have 5 8 , or 13 petals.
As was previously mentioned, the Fibonacci sequence occurs very often in nature, not only in number form, but also as a spiral. Very often it appears in flora, such as in the arrangement of seeds on flowering plants, the number of petals in sunflowers, or even "phyllotaxy" which is the arrangement of leaves around the stem (Britton, 2011). Of course, plants and flowers do not have minds and do not actually realise that they grow in this way. According to scientists, certain flora develop in the most efficient way based on the biochemistry of plants as they develop new structures such as leaves or flowers which provides an evolutionary advantage in promoting the plant's survival (Rehmeyer, 2007).

Although this is the common belief, researchers are still not entirely sure whether this is the complete answer. Mathematicians Auguste and Louis Bravais were the first to find a mathematical proof which depicted that a certain angle regulated the growth of plants (Smith, 2013, p. 66). They measured the angle between successive primordia as they migrated from the centre of the apex of a flower finding that an "angle of divergence" occurred which was conditioned by Fibonacci numbers (Smith, 2013, p. 66). Their research, however, promoted more questions about why flora develop the sequence in the first place (Rehmeyer, 2007).

\section{"Scientists have not entirely solved the mystery, but an idea seems to be emerging..."}

(JULIE REHMEYER, 2007) 


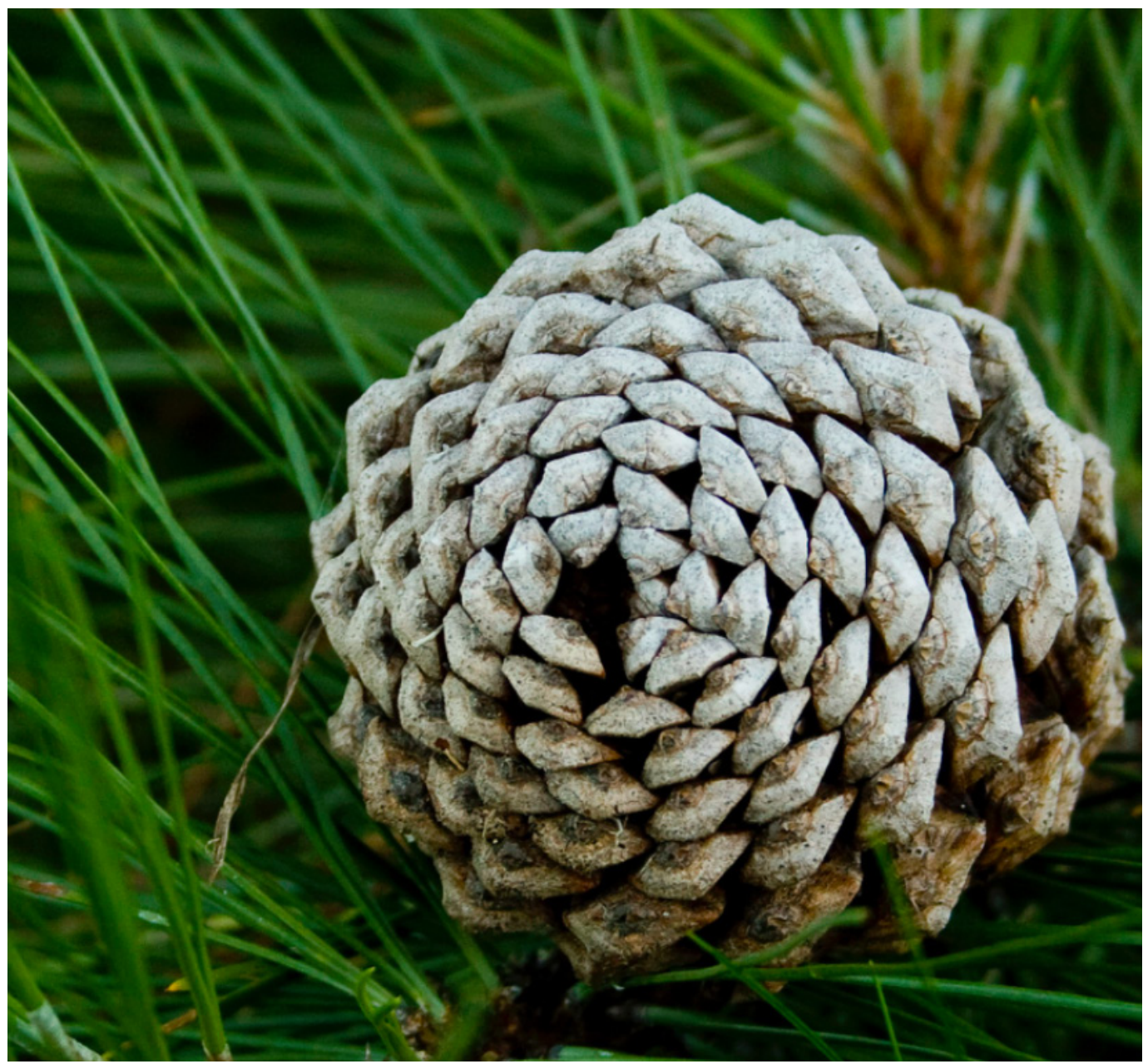

PINECONE PRINCIPLES

Pinecones, along with pineapples, seem to illustrate perfect examples of the Fibonacci sequence.

All pinecones develop in a spiral shape which starts from the base where it was connected to the tree (Carson, 1978, p. 134). There are usually two sets of spirals which circulate in different directions up to the top of the pinecone (Dunlap, 1997, p. 130).In some cases, a pinecone is found not to incorporate the sequence which is usually due to deformities caused by pests (Carson, 1978, p. 135).

The spiralled bracts going in opposing directions are adjacent Fibonacci numbers as is depicted in the images below (Simmons, 2011).

The same pinecone has 8 spirals in one direction yet thirteen in the other (Dunlap, 1997, p.130). The sequence is an approximation to an irrational number meaning that the bracts of pinecones should not line up (Collins, 2011). If they did, the pinecone would be weakened and susceptible to breakage (Collins, 2011). 

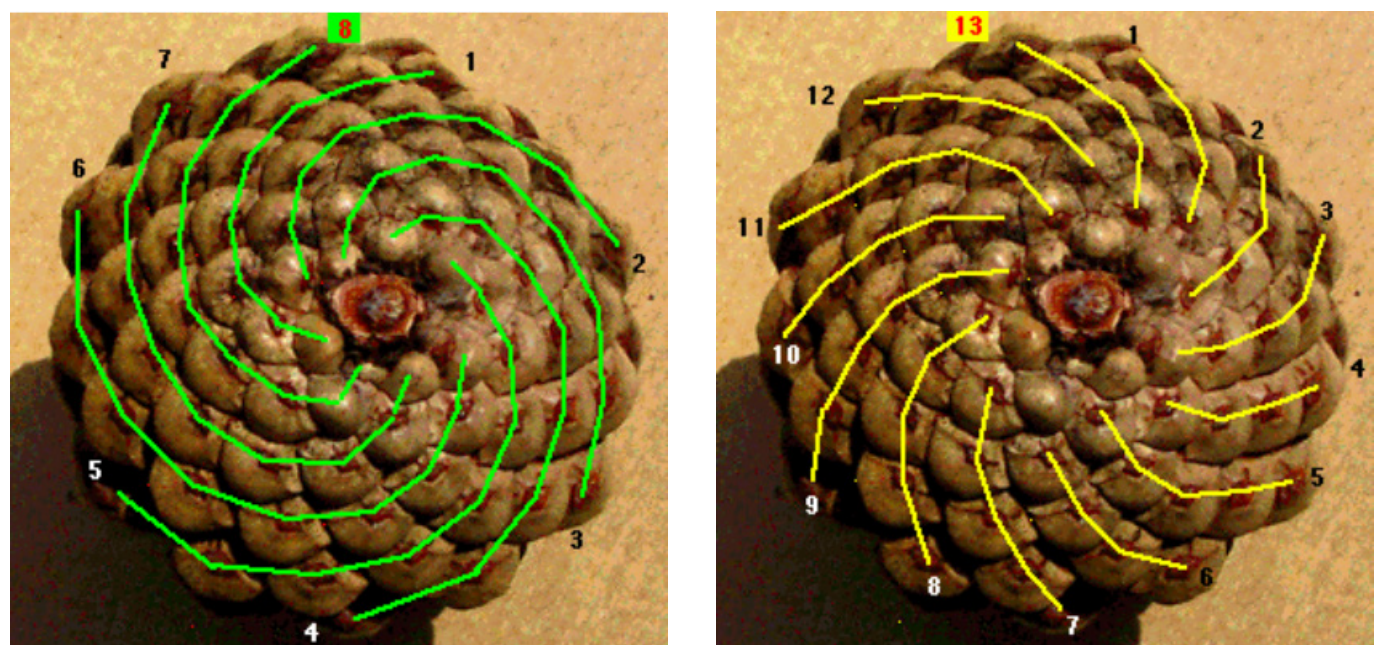

Peterson (1992) describes how a mathematical model of sunflower floret and seed development was created which illustrated how the florets are produced one by one at the flower's centre, pushing the other florets outward. This is the same thing that happens with pinecones. Every bract settles into a position which happens to have a specific constant angle of rotation pertinent to the position of the last bract, and this is what creates the spiral pattern (Peterson, 1992).

Naylor (2002, p. 163) states that these spirals can be easily simulated: assume that there are k bracts in the arrangement where the most recent is "1" and the previous bracts are 2, 3, 4, etc. so that the most further bract is $k$. Given that each bract has an area of 1 , then the circular face area is $k$ and the radius is $\sqrt{ } k / \pi$. This makes the gap between the centre of the pinecone to each bract proportional to the square root of its bract number. As the angle " $\alpha$ " between any two bracts is constant, the angle of bract $k$ is simply $k \alpha$.

\section{SEED HEADS AND SUNFLOWERS}

The Fibonacci sequence allows for the maximum number of seeds in an arrangement of seeds in the seed heads of sunflowers (Grob et al., 2007, p. 857). There is no crowding in the centre and no spaces at the edges meaning that the sunflower has the perfect space organisation for its seeds (Grob et al., 2007, p. 857). This is due to a growth characteristic of sunflowers (Segerman, 2002, p. 1). Individual seeds grow at the center of the flower and continue adding seeds pushing those on the edge outwards (Heimbuch, 2002). As it develops in a Fibonacci arrangement, seeds are always grouped uniformly and they stay compact (Heimbuch, 2002).

To optimally fill the sunflower head with the highest amount of seeds, the most irrational number should be used, which is phi, otherwise known as the golden ratio (Winer, 2013). The approximation for phi is as follows:

$$
x_{n}=\frac{F_{n+1}}{F_{n}}
$$

Where $F n$ is the $n^{\text {th }}$ Fibonacci number.

Using this irrational number to spread out, the seeds makes it harder to see the number of lines in the spiral of a sunflower; however, this means that the distribution is maximally efficient (Winer, 2013). If the spaces between different spirals were easy to see, it would signify that this space is "wasted" and therefore not being effectively utilised (Winer, 2013). 


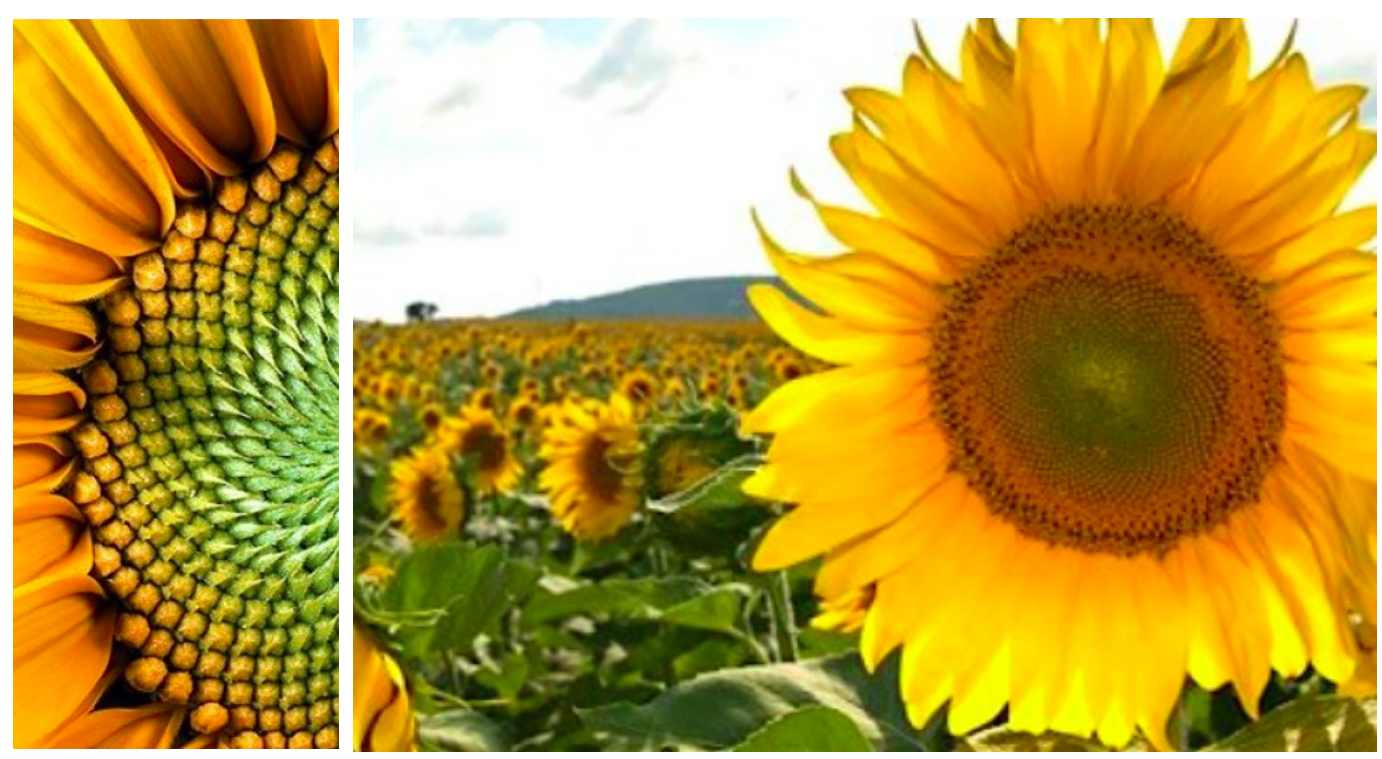

The Fibonacci metric, $M(n)$, is defined as the number of terms in the Zeckendorf representation of $n$ (Segerman, 2002, p. 1). Zeckendorf's theory declares states that all positive integers can be illustrated as a sum of precise Fibonacci numbers, as long as there is an additional condition that no two adjacent Fibonacci numbers are used (Segerman, 2002, p. 1). Colouring sunflowers according to the Fibonacci metric illustrates subtle connections between the spiral and the sequence as is seen in the image below (Segerman, 2002, p. 3).

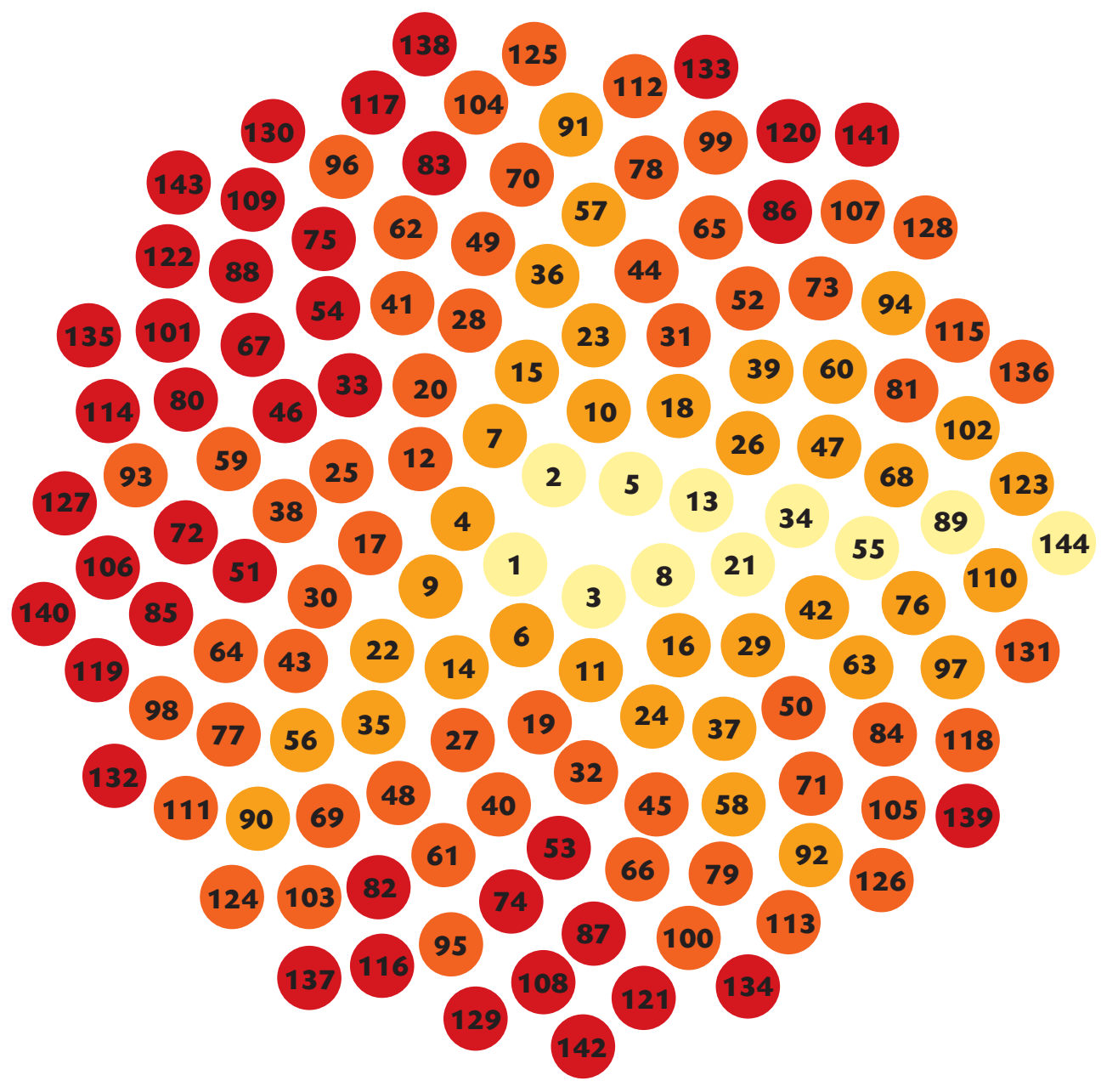



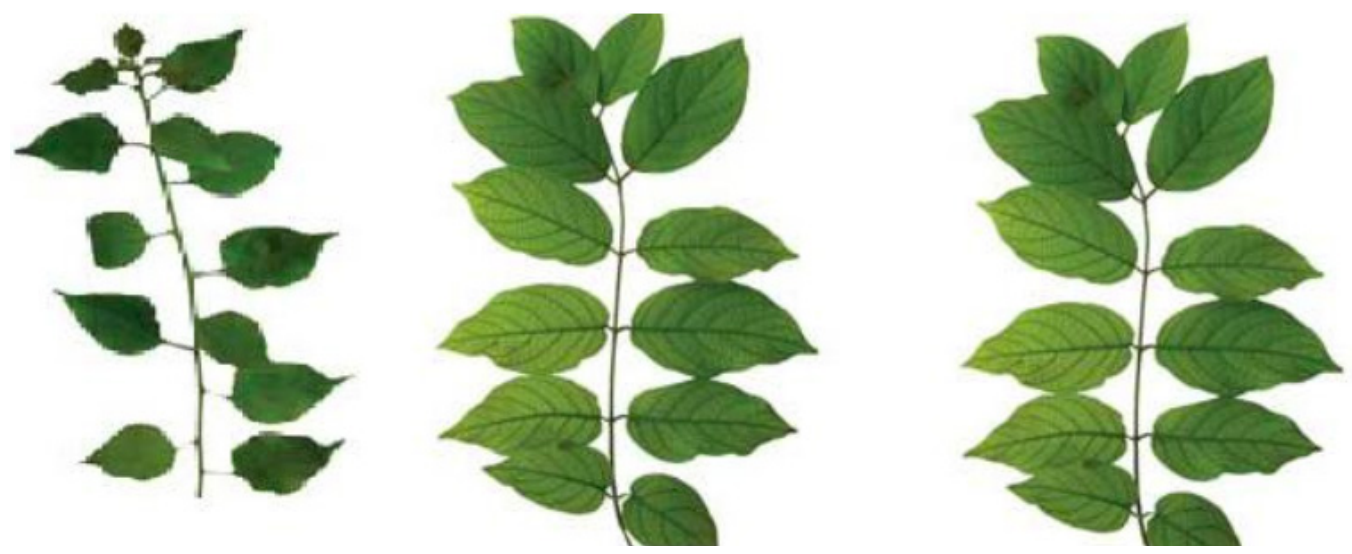

\section{LEAF ARRANGEMENT: PHYLLOTAXIS}

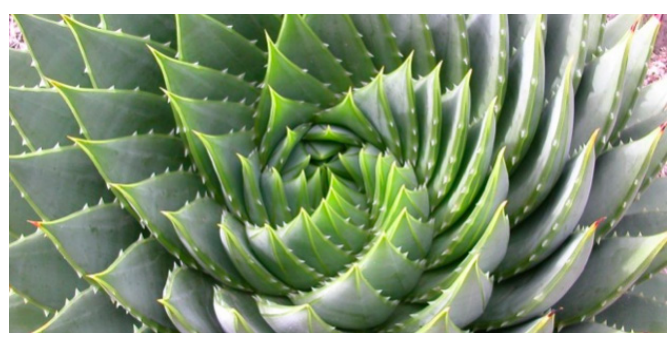

Phyllotaxis is the arrangement of leaves around a stem. There are two different main types of leaf arrangements in the world: one is where the leaves spring from opposite sides of each other in a decussate pattern, and the other is the spiral pattern which displays the Fibonacci pattern (Mitchison, 1977, p. 270).

According to Mitchison (1977, p. 274) Fibonacci phyllotaxis is a mathematical requirement for the expanding apex of a plant which provides appropriate spacing for the positioning of new leaves. It is noted as a "stable mathematical phenomenon" which seems to appear everywhere, not only in flora, but in nature (Mitchison, 1977, p. 278). As previously discussed, similar to the distribution of seeds on a sunflower head, the arrangement of successive leaves are separated by phi (University of Chicago, 2013, p. 1). This means that they are optimally distributed and have the best access to sunlight which is realised by inanimate physical systems (University of Chicago, 2013, p. 1).

\section{SEED ARRANGEMENTS IN OTHER FLOWERS}

Seed arrangements can be found in all different types of flowers as is seen on this page. Like sunflowers, which were discussed in a previous section, the majority of flowers have two sets of spirals which go in opposite directions (Knott, 2010). The number of spirals going in both ways is almost always adjacent Fibonacci numbers (Peterson, 2006). Very often it happens that there are 55 and 34 spirals.
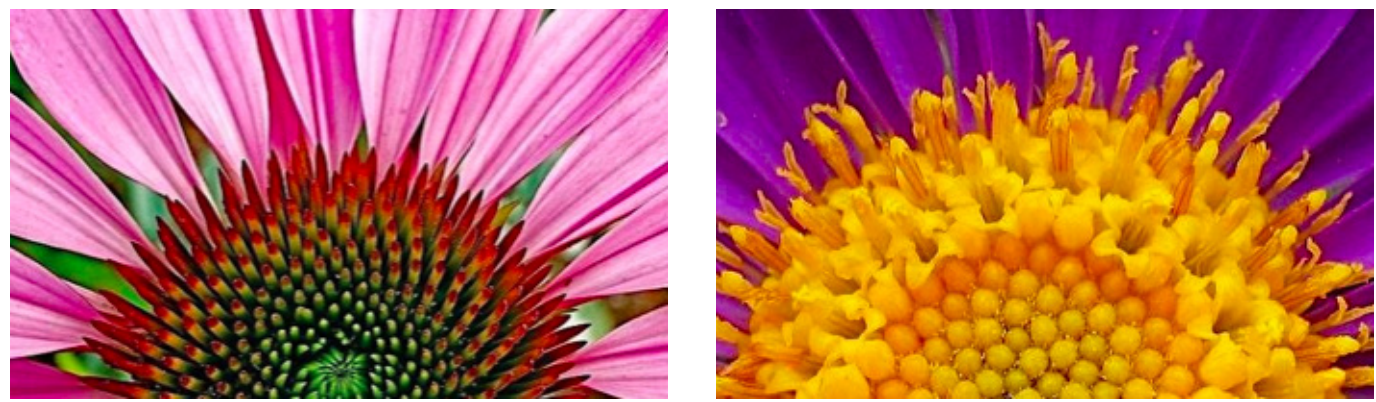

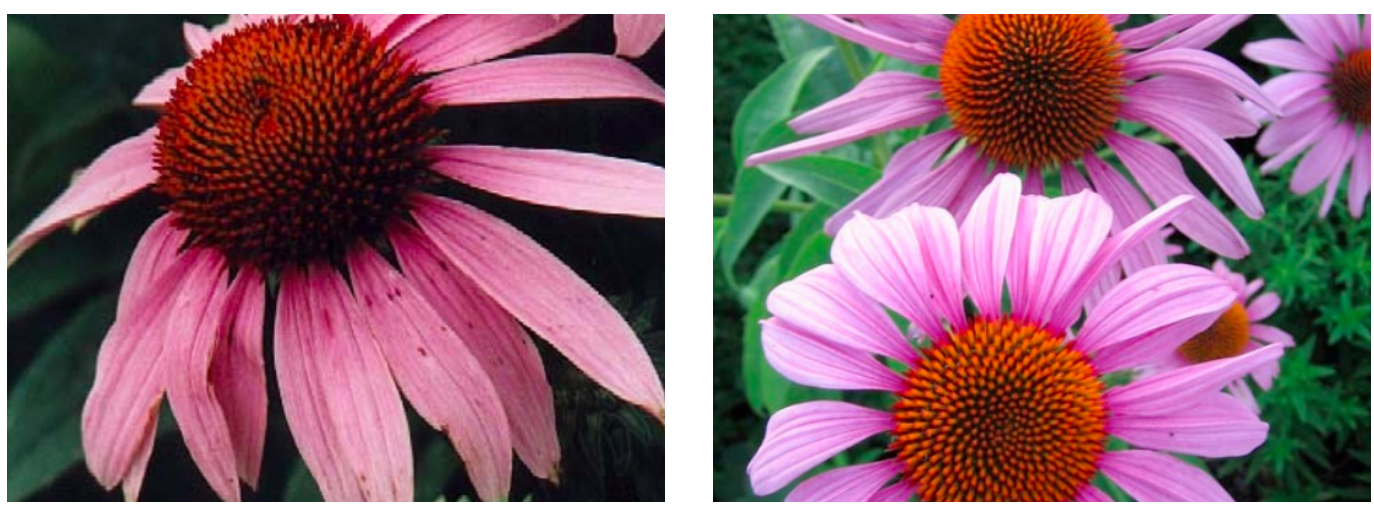

PRETTY PETALS AND PERFECT SPIRALS

Most people have never taken the time to look at flowers and to really notice them. If you have, you would have realised that almost all flowers have a certain number of petals.

Lillies have 3 petals. Buttercups and wild roses have 5. Delphiniums have 8, and cinerarias have 13. Most asters have 21 petals. While ordinary field daisies have 34 petals, other types can have 55 or 89 petals.

Some of these flowers are very specific and always have a Fibonacci number of petals while others are not as precise with the number, but still average a Fibonacci number (Peterson, 2006). In such cases, it is more likely that underdevelopment occurred and the flower has one or two petals less than it is meant to (Peterson, 2006). As with most flora, the reason for these amounts of petals has to do with maximising the efficiency of light during the growth process of plants (Knott, 2010).
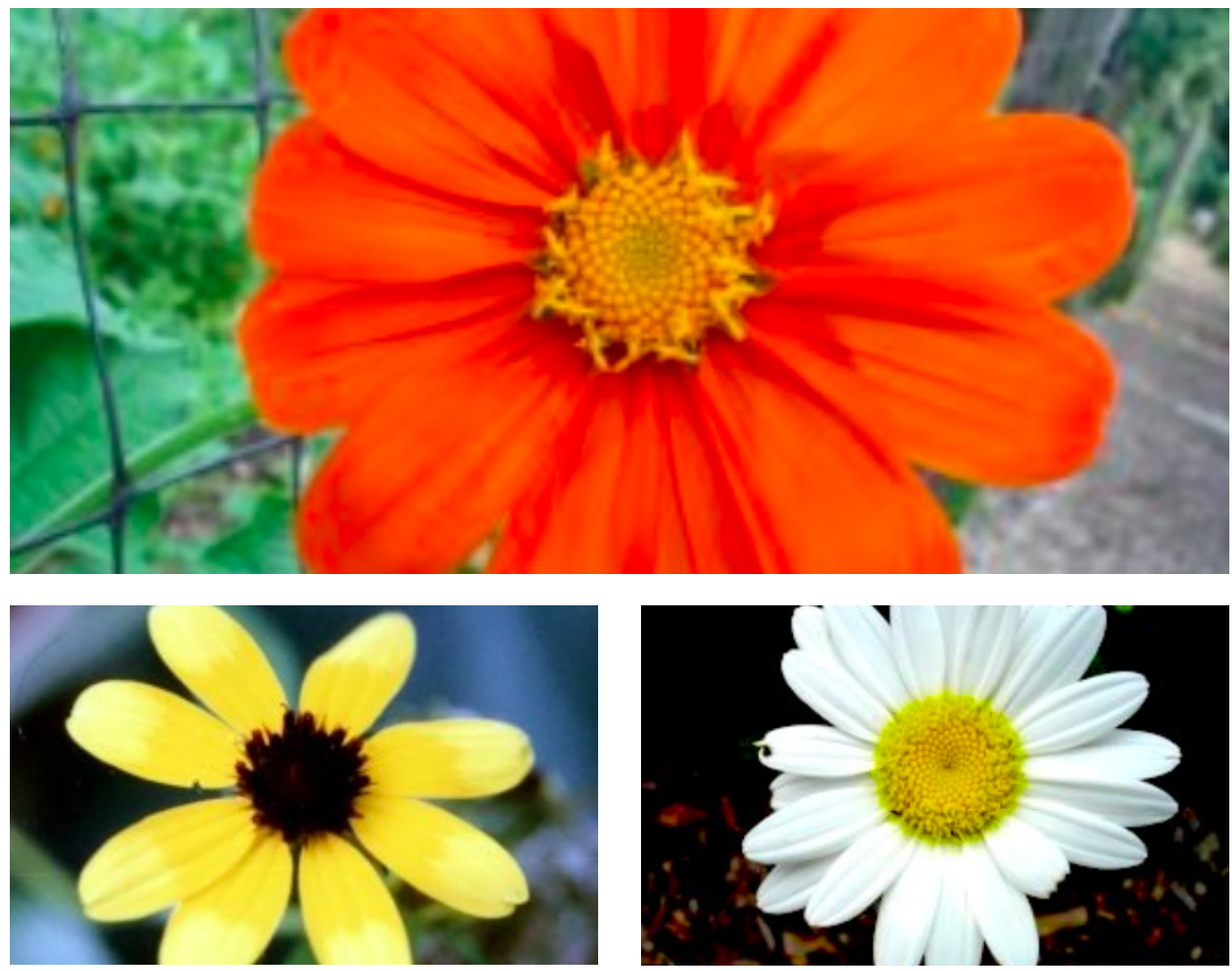
Rose petals develop in a distinct Fibonacci pattern, where each new set grows between the spaces of the previous set (Peterson, 2006). This means that the more developed petals will not steal light from the newer petals (Peterson, 2006).

It is obvious after some time that the average angle the petals utilise while developing is 137.5 degrees (Johnson, 2013). This is the most effective way of giving as much needed sunlight to each petal as is necessary (Johnson, 2013). If any two adjacent rose petals are taken and divided, their value is always equivalent to phi, the Golden Ratio (Peterson, 2006).
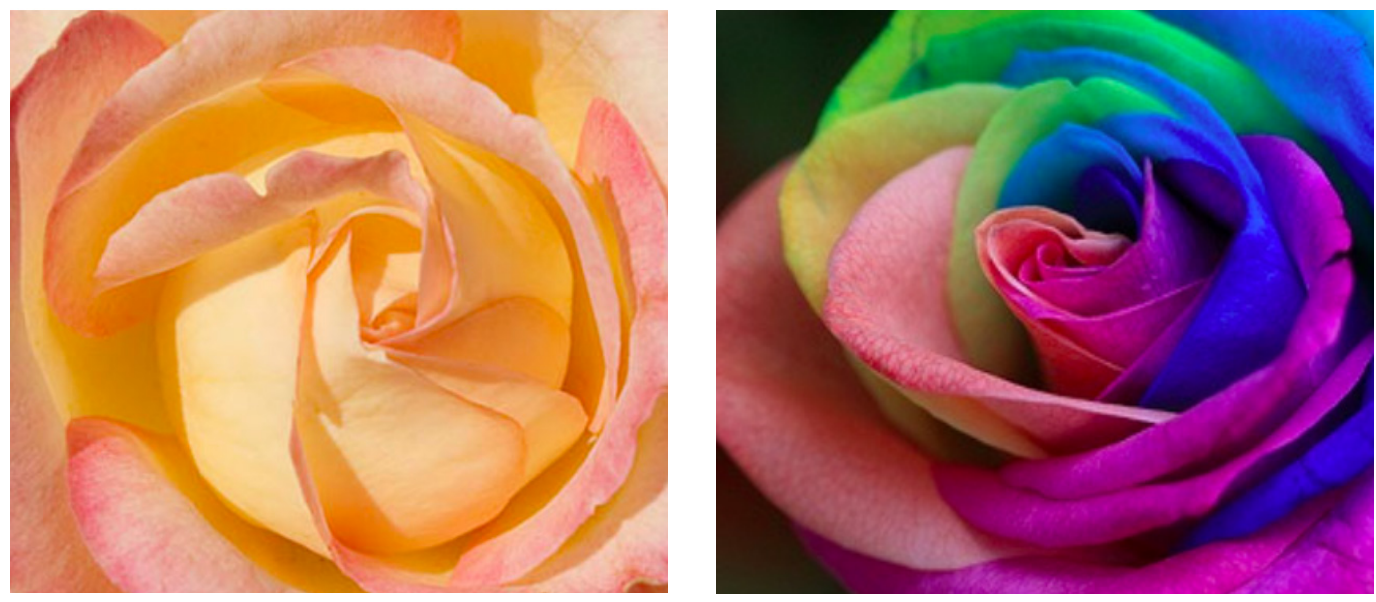

\section{HOW TO CREATE RAINBOW ROSES}

The Fibonacci sequence can be implemented when creating "rainbow roses" (Osterrieder, 2012). This technique was developed by Peter van de Werken with his knowledge of plant phyllotaxy (Osterrieder, 2012). The arrangement of rose petals means that the first and sixth petal will be on the same vertical line (Osterrieder, 2012). By cutting the stem into four equal parts and placing each part into different coloured water, the petals change colour depending on which position in the spiral they have (Sarang, 2013).

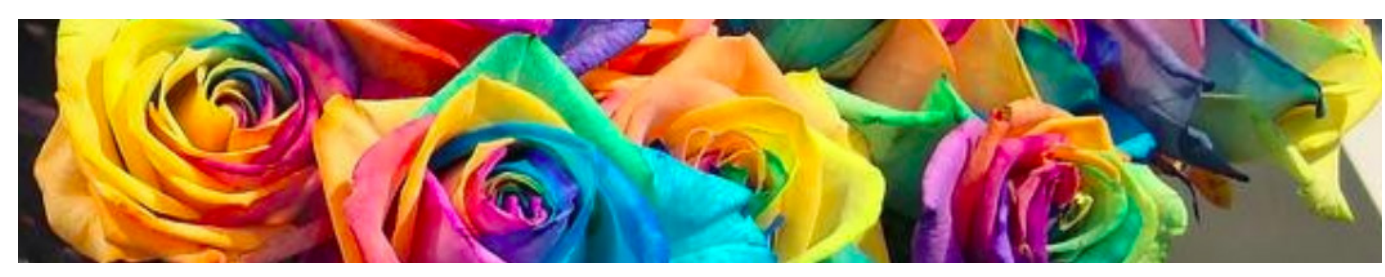

\section{CONCLUSION}

Throughout this report, it can be seen that the mathematical properties of the Fibonacci sequence is found in many places in nature, mainly flora. Flower petals and leaves grow in Fibonacci numbers. Sunflower seeds grow on the seed heads in spirals correlating to the sequence as do the bracts of pinecones.

Although there has been extensive research into the topic, scientists and mathematicians are still not completely sure why this sequence seems to pop up everywhere. It has been presumed that it is just nature's way of getting maximum resources available to it, and taking the easiest path to these goals. 


\section{REFERENCES}

Britton, J. (2011) Fibonacci Numbers in Nature. Available at: http://britton.disted.camosun.bc.ca/fibslide/jbfibslide.htm (Accessed: 19 January 2014).

Brown, C. (2010) Bloomberg Professional: Fibonacci Analysis. New York: Bloomberg Press.

Collins, D. (2011) Mona Lisa and Fibonacci Pinecones. Available at: http://www.warren-wilson.edu/ physics/PhysPhotO fWeek/2011PPOW/20110225FibonacciPinecone/ (Accessed: 19 January 2014).

Carson, J. (1978) 'Fibonacci Numbers and Pineapple Phylloaxy', The Two-Year College Mathematics Journal, 9(3), pp. 132-136, MAOA. [Online]. Available at: http://www.jstor.org/stable/3026682 (Accessed: 19 January 2014).

Dunlap, R. A. (1997) The Golden Ratio and Fibonacci Numbers. Google eBooks [Online]. Available at: http://books. google.de/ books?id=Pq 2AekTsF6oCerpg=PA130erdq=fibonacci+pineconeerhl=enersa=Xerei=M4frUruJMYKVtQa aylHQDAErved=0CC4Q6AEwAA\#v=onepageerq=fibonacci\%20pineconeerf=false (Accessed: 5 January 2014).

Grob, V., Pfeifer, E. and Rutishauser, R. (2007) 'Sympodial Construction of Fibonacci Type Leaf Rosettes in Pinguicula Moranesis', Annals of Botany, 100(4), pp. 857-863. Oxford Journals. [Online]. Available at: http://aob.oxfordjournals. org/content/100/4/857.full (Accessed: 24 January 2014)

Heimbuch, J. (2012) Nature Blows My Mind! The Hypnotic Patters of Sunflowers. Available at: http://www.treehugger. com/slideshows/natural-sciences/nature-blows-my-mind-hypnotic-patterns-sunflowers/ (Accessed: 24 January 2014).

Johnson, W. (2013) Are Roses in the Golden Ratio? Available at: http://www.ehow.com/info_8720076_roses-goldenratio.html (Accessed: 28 January 2014).

Knott, R. (2010) Fibonacci Numbers and Nature. [Online]. Available at: http://www.maths.surrey.ac.uk/hosted-sites/R. Knott/Fibonacci/fibnat.html (Accessed: 5 January 2014).

Mitchison, G. J. (1977) 'Phyllotaxis and the Fibonacci Series', Science: New Series, 196(4287), pp 270-275. AAAS [Online]. Available at: http://www.johnboccio.com/courses/Physics120_2008/docs/mitchison.pdf (Accessed: 24 January 2014).

Naylor, M. (2002) Golden, $\sqrt{2}$, and $\varpi$ Flowers: A Spiral Story. [Online]. Available at: http://www.mike-naylor.com/ resources/naylor-seeds.pdf (Accessed: 19 January 2014).

Norton, A. (1999) 'Fibonacci and the Golden Ratio', Mathematics Magazine, 75(3), pp. 163-172, WWU. [Online]. Available at: http://jwilson.coe.uga.edu/EMT668/EMT668.folders.F97/Norton/Final/Fibonacci.html (Accessed: 5 January 2014).

Osterrieder, A. (2012) Roses are Red - But They Don't Have to Be. Available at: http:/ /aobblog.com/2012/02/roses-arered-but-they-dont-need-to-be-if-you-know-how-to-use-food-dyes-and-fibonacci/ (Accessed: 28 January 2014).

Peterson, I. (2006) Fibonacci's Missing Flowers. Available at: https://www.sciencenews.org/article/fibonaccis-missingflowers (Accessed: 28 January 2014)

Rehmeyer, J. (2007) The Mathematical Lives of Plants. Available at: http://www.sciencenews.org/article/mathematicallives-plants (Accessed: 19 January 2014).

Sarang, K. (2013) Rainbow Rose. Available at: http://awescience.com/2013/05/26/rainbow-rose/ (Accessed: 28 January 2014).

Segerman, H. (2010) The Sunflower Spiral and the Fibonacci Metric. [Online]. Available at: http://ms.unimelb.edu. $\mathrm{au} /$ segerman/papers/sunflower_spiral_fibonacci_metric.pdf (Accessed: 24 January 2014).

Simmons, J. R. (2011) Fibonacci Numbers and Nature. Available at: http://jwilson.coe.uga.edu/EMAT6680/Simmons/ Essay1/6690ProjectFibonacciF.htm (Accessed: 19 January 2014).

Smith, P. (2013) Climate Change and Cultural Heritage: A Race Against Time: Routledge Explorations in Environmental Studies, 1st edn. London: Routledge.

University of Chicago (2013) Phyllotaxis, the Golden Ratio and the Fibonacci Sequence. [Online]. Available at: http://jfi. uchicago.edu/ efrati/compton/handout8.pdf (Accessed: 28 January 2014).

Winer, M. C. (2013) Fibonacci Numbers in Sunflowers. Available at: http://www.martincwiner.com/fibonacci-numbersin-sunflowers/ (Accessed: 24 January 2014). 
PAGE 6: Horniak, D. (2013) Pink Flowers [Photograph]. Photo taken exclusively for this paper. Photographer's gallery: http://www.totem.cz/galerie.php?ot1=25erot2=21798

PAGE 7: Grizdave (2011) Math Pine Cone. Flickr [Online]. Available at: http://www.flickr.com/photos/ grizdave/2736846377/ (Accessed: 27 December 2013).

PAGE 8, LEFT: Knott, R. (2005) Fibonacci Pine Cone [Online]. Available at: http://personal.maths.surrey.ac.uk/ext/R. Knott/Fibonacci/fibnat.html (Accessed: 27 December 2013).

PAGE 8, RIGHT: Knott, R. (2005) Fibonacci Pine Cone [Online]. Available at: http://personal.maths.surrey.ac.uk/ ext/R.Knott/Fibonacci/fibnat.html (Accessed: 27 December 2013).

PAGE 9, TOP LEFT: Stockbyte (2008) Sunflower. Stockbyte [Online]. Available at: http:/ /media.treehugger.com/ assets/images/2012/08/71044124-th.jpg.644x0_9100_crop-smart.jpg (Accessed: 27 December 2013).

PAGE 9, TOP RIGHT: Sefaoncul (2011) Sunflowers. iStockphoto [Online]. Available at: http://www.pbs.org/wgbh/ nova/assets/img/describing-nature-math/image-05-large.jpg (Accessed: 27 December 2013).

PAGE 9, BOTTOM: Segerman, H. (2010) The Sunflower Spiral and the Fibonacci Metric [Online]. Available at: http:// ms.unimelb.edu.au/ segerman/papers/sunflower_spiral_fibonacci_metric.pdf (Accessed: 24 January 2014).

PAGE 10, TOP: Kshitij Education India (2013) Different Types of Phyllotaxy [Online]. Available at: http:/ /www.kshitij-school. com/Study-Material/Class-11/Biology/Morphology-of-flowering-plants/Leaf/3.jpg (Accessed: 22 January 2014).

PAGE 10, CENTER LEFT: Hamamatsu, F. (2012) Avage Spiral [Online]. Available at: http:/ /fractalfoundation.org/ OFCA/agavespiral.jpg (Accessed: 24 January 2014).

PAGE 10, воттоM LEFT: Baab1 (2008) Fibonacci Flower. Flickr [Online]. Available at: http:/ / www.flickr.com/ photos/9738004@N08/2593294045 (Accessed: 27 December 2013).

PAGE 10, BOTTOM RIGHT: Jansson, S. (2006) The Divine Proportion. Flickr [Online]. Available at: http:/ /www.flickr. com/photos/41894180985@N01/171302091 (Accessed: 27 December 2013).

PAGE 11, TOP LEFT: Werk, R. (2003) Purple Coneflower [Online]. Available at: http:/ /www.ndsu.edu/pubweb/ chiwonlee/plsc211/student\%20papers/articles03/rachel.werk/purple-coneflower.jpeg (Accessed: 20 January 2014).

PAGE 11, TOP RIGHT: Knapp, S. B. (2013) Fibonacci Flowers [Online]. Available at: http://1.bp.blogspot.com/-

GTPAFW1W-Nk/UXtE2PYcXVI/AAAAAAAALeg/yTJcXjJ8CPU/s1600/500Coneflower.jpg (Accessed: 20 January 2014).

PAGE 11, CENTER: Peterson, K. (2011) Fibonacci Flower [Online]. Available at: https://www.sciencenews.org/sites/ default/files/5907 (Accessed: 23 January 2014).

PAGE 11, BOTTOM RIGHT: Peterson, K. (2011) Fibonacci Flower [Online]. Available at: https:/ /www.sciencenews. org/sites/default/files/5906 (Accessed: 23 January 2014).

PAGE 11, ВОтTOM LEFT: Peterson, K. (2011) Fibonacci Flower [Online]. Available at: https:/ / www.sciencenews. org/sites/default/files/5910 (Accessed: 23 January 2014).

PAGE 12, TOP LEFT: Computer Images (2011) Fibonacci Rose [Online]. Available at: http:/ / www.computerimages. com/photo_gallery/photos16.html (Accessed: 27 December 2013).

PAGE 12, TOP RIGHT: INTVGene (2008) Rainbow Rose. Flickr [Online]. Available at: http:/ / www.flickr.com/ photos/intvgene/2618479990/ (Accessed: 7 January 2014).

PAGE 12, BOTTOM: Wanorizan (2014) Rainbow Roses [Online]. Available at: http:/ /alldaychic.com/rainbow-rosesdiy/ (Accessed: 18 March 2014). 